\title{
Research on New Energy Establishment of Power Generation and Structure Model
}

\author{
Peng Gao \\ Jinzhou Power Supply Branch \\ State Grid Liaoning Electric Power Supply Co. Ltd \\ Jinzhou, China \\ e-mail: liyuca@126.com
}

\author{
Yunlin Guan \\ Jinzhou Power Supply Branch \\ State Grid Liaoning Electric Power Supply Co. Ltd \\ Jinzhou, China \\ e-mail:ylg156@163.com
}

\begin{abstract}
Traditional power supply system with the method of centralized power generation, and then use electricity transmission network transmit electricity to the user. Research model is the basis of the research on the subsequent issue, how to set up a valid practical problems but not entirely confined to the actual problem and has good adaptability model is valuable to determine whether the results of one of the key. the model is based on the Washington university school of electrical IEEE 30 "power structure as the foundation. New energy in power generation system generally includes wind power, photovoltaic power station and key components such as energy storage power station. This paper will design a reasonable system structure, using universal transmission line structure simplifies the structure of the power supply system; comparative analysis of advantages and disadvantages of various optimization algorithms. The final choice of primal dual optimization algorithm as optimizing kernel algorithm.
\end{abstract}

Keywords-New Energy; Power Generation; Power Structure; Model

\section{INTRODUCTION}

Power is the basis of the continuous development of modern science and technology, is the important guarantee of improving human life quality, is the lifeblood of the national economy and security. Traditional power supply system with the method of centralized power generation, and then use electricity transmission network transmit electricity to the user. Electric power development has experienced two important milestones: first, in 1882, Edison in the United States New York Pearl Street Station built the world's first direct current generator driven by a steam engine send electricity system formed by dc, marks the beginning of the era of power; Second, Germany in 1891 established the first by the ac generator power generation, and then through the length of $179 \mathrm{~km}$, the voltage level of $12 \mathrm{kv}$ transmission lines transmit power transmission system, a symbol of the modern ac supply system the establishment of the basic patterns[1].

For distributed at home and abroad research achievements of new energy power generation, but those results are mainly limited in the study of unilaterally. For example research power prediction only consider forecasting precision and no effect on the capacity of energy storage device; The energy storage device only consider how to select energy storage device and no late combined with energy storage devices in the network behavior[2-5]. In addition, the new energy research hotspot focused on its implementation in form, such as the topology of the inverter, harmonic elimination circuit design and the energy of fine management, etc[6-8]. In this paper, design a reasonable system structure, load fluctuation curve and new energy power generation curve, select reasonable optimization algorithm.

\section{SYSTEM NETWORK STRUCTURE}

In this paper, we study the model is based on the Washington university school of electrical IEEE 30 "power structure as the foundation, its topology structure as shown in Fig .1. Node 1 is the fossil fuel power generation, its power can be in the upper limit of power generation and power between the lower volatility, on behalf of peaking power plants or rotating standby unit in the system; Node 2 for fossil fuel power generation, its capacity is constant value, represent a base load power generation part of the system; Node 5 for wind power, the electricity changing with wind size; Node for solar power generation, power change with sunlight irradiation intensity; Node 7 for wave load node, the electricity demand changes over time, on behalf of the dynamic load in the system; The rest of the node demand of electricity is constant value, represent a base load part of the system. At the same time, in order to simulate energy storage power station in the system influence and power characteristics, node 5 and 8 respectively is configured with a certain amount of energy storage device[9]. This paper used load data as shown in table 1 .

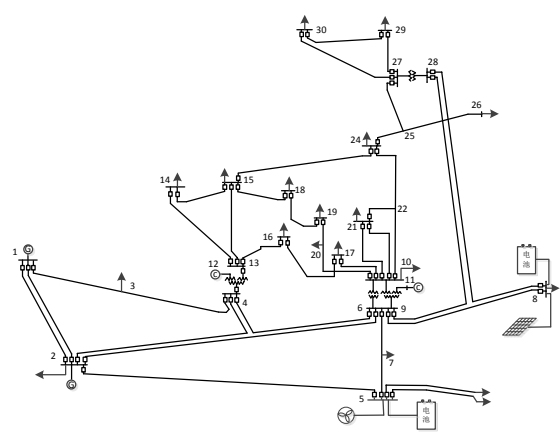

Figure 1. System network topology 
TABLE I. NODE LOADS

\begin{tabular}{|c|c|c|c|c|c|}
\hline Node & $\begin{array}{c}\text { Load } \\
\text { capacity }\end{array}$ & Node & $\begin{array}{c}\text { Load } \\
\text { capacity }\end{array}$ & Node & $\begin{array}{c}\text { Load } \\
\text { capacity }\end{array}$ \\
\hline 1 & 0 & 11 & 0 & 21 & 17.5 \\
\hline 2 & 21.7 & 12 & 11.2 & 22 & 0 \\
\hline 3 & 2.4 & 13 & 0 & 23 & 3.2 \\
\hline 4 & 7.6 & 14 & 6.2 & 24 & 8.7 \\
\hline 5 & 94.2 & 15 & 8.2 & 25 & 0 \\
\hline 6 & 0 & 16 & 3.5 & 26 & 3.5 \\
\hline 7 & Change & 17 & 9 & 27 & 0 \\
\hline 8 & 30 & 18 & 3.2 & 28 & 0 \\
\hline 9 & 0 & 19 & 9.5 & 29 & 2.4 \\
\hline 10 & 5.8 & 20 & 2.2 & 30 & 10.6 \\
\hline
\end{tabular}

Universal model contains $\pi$ type structure of transmission line, the series impedance for $Z_{s}=r_{s}+j x_{s}$; A parallel structure of capacitive reactance, the capacitive reactance to $b_{c}$; An ideal phase shifting transformer, the impedance of 0 , only phase shift effect, there is no loss of energy. Ideal phase shift change than the value of $\tau$, phaseshifting Angle for $\theta_{\text {shift }}$. The structure schematic is shown in Fig .2.

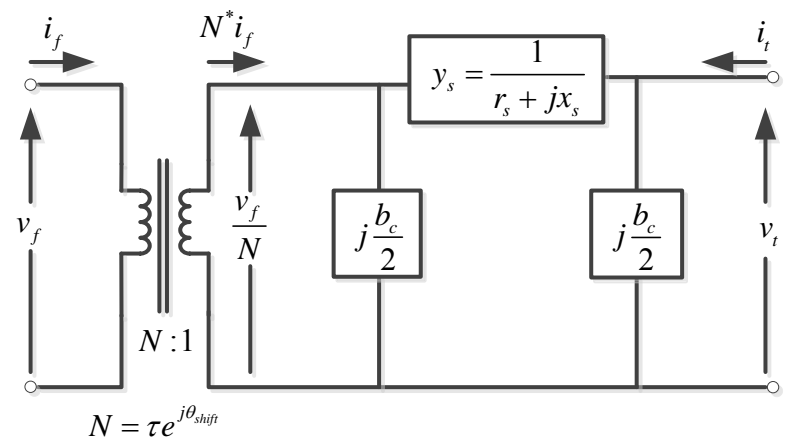

Figure 2. The general model of transmission lines, transformers and phase shifter

In the form of $i_{f}$ plural beginning injection current injection current and end $i_{t}$, each variable in the model of solving solution can be obtained using the method of node voltage, the computational expressions can be represented with two order matrix. (1) is for the node admittance matrix, pattern of (2) for the use of the node voltage method to solve the related variables used in the process of equations.

$$
Y_{b r}=\left(\begin{array}{cc}
\left(y_{s}+j \frac{b_{c}}{2}\right) \frac{1}{\tau^{2}} & -y_{s} \frac{1}{\tau e^{j \theta_{\text {shift }}}} \\
-y_{s} \frac{1}{\tau e^{j \theta_{\text {shift }}}} & y_{s}+j \frac{b_{c}}{2}
\end{array}\right)
$$

$$
\left(\begin{array}{c}
i_{f} \\
i_{t}
\end{array}\right)=Y_{b r}\left(\begin{array}{c}
v_{f} \\
v_{t}
\end{array}\right)
$$

\section{LOAD FLUCTUATION LOAD CURVE DESIGN}

Electric power system in the network users demand for energy is to change all the time, to simulate new energy access to the system after the actual electric network, need to join a dynamic load in the electric network[10]. In the power system load change is conform to certain rules, although it will not be conflict with the actual physical meaning, for example, generally do not appear, such as large pulse load fluctuation trend, but also exist obvious relevant features, such as lamp of peaks and troughs. In order to ensure that the dynamic load curve and actual basic consistent, the design of load curve should contain peaks and troughs and the main characteristics of curve error. This paper adopts the design principle such as shown in (3).

$f_{\text {laod_v }}(t)=g\left(t, \delta_{\text {peak }}, \delta_{\text {valley }}, P_{\text {fixed_mean }}, P_{v_{-} \text {mean }}, \delta_{\text {vibration }}\right.$, per $)(3)$

Type 2.4 and type 2.5 calculation principle for the design process.

$$
\begin{gathered}
\text { per }=\frac{\delta_{\text {peak } / \text { valley }}}{P_{\text {fixed_mean }}+P_{v_{-} \text {mean }}} \times 100 \\
\delta_{\text {peak }}=\frac{\operatorname{per} \cdot P_{\text {fixed_mean }}+p e r \cdot P_{\mathrm{v}_{-} \text {mean }}}{100}
\end{gathered}
$$

In order to simplify the analysis, this paper USES the sine wave function to simulate the dynamic load curve, set curve

peaks and troughs of volatility percentage is $30 \%$. By (6) shows the average of the sine function, the function of peak and average difference model for, average value and function

in the valley of the differential mode for. The above value

generation in (4) easy solution for type is shown in (7).

$$
\begin{gathered}
f(t)=A \sin (t-T)+A \\
A=\frac{p e r \cdot P_{\text {fixed_mean }}}{100-\text { per }}
\end{gathered}
$$

The parameter values of the dynamic load fluctuation data as shown in table 2 . 
TABLE II. DYNAMIC LOAD CURVE DATA

\begin{tabular}{|c|c|c|c|c|c|}
\hline $\begin{array}{c}\text { Time } \\
\text { Point }\end{array}$ & $\begin{array}{c}\text { Amount } \\
\text { of } \\
\text { volatility }\end{array}$ & $\begin{array}{c}\text { Time } \\
\text { Point }\end{array}$ & $\begin{array}{c}\text { Amount } \\
\text { of }\end{array}$ & $\begin{array}{c}\text { volatility } \\
\text { Point }\end{array}$ & $\begin{array}{c}\text { of } \\
\text { volatility }\end{array}$ \\
\hline 1 & 0.665355 & 21 & 192.8479 & 50 & 170.8582 \\
\hline 2 & 2.65413 & 22 & 202.7278 & 51 & 158.9895 \\
\hline 3 & 5.944536 & 23 & 211.7174 & 52 & 146.7095 \\
\hline 4 & 10.50052 & 24 & 219.718 & 53 & 134.1529 \\
\hline 5 & 16.27217 & 25 & 226.6421 & 54 & 121.4571 \\
\hline 6 & 23.19625 & 26 & 232.4138 & 55 & 108.7614 \\
\hline 7 & 31.1969 & 27 & 236.9698 & 56 & 96.20478 \\
\hline 8 & 40.18645 & 28 & 240.2602 & 57 & 83.92482 \\
\hline 9 & 50.06643 & 29 & 242.2489 & 58 & 72.05607 \\
\hline 10 & 60.72857 & 30 & 242.9143 & 59 & 60.72857 \\
\hline 11 & 72.05607 & 31 & 242.2489 & 60 & 50.06643 \\
\hline 12 & 83.92482 & 32 & 240.2602 & 61 & 40.18645 \\
\hline 13 & 96.20478 & 33 & 236.9698 & 62 & 31.1969 \\
\hline 14 & 108.7614 & 34 & 232.4138 & 63 & 23.19625 \\
\hline 15 & 121.4571 & 35 & 226.6421 & 64 & 16.27217 \\
\hline 16 & 134.1529 & 36 & 219.718 & 65 & 10.50052 \\
\hline 17 & 146.7095 & 37 & 211.7174 & 66 & 5.944536 \\
\hline 18 & 158.9895 & 38 & 202.7278 & 67 & 2.65413 \\
\hline 19 & 170.8582 & 39 & 192.8479 & 68 & 0.665355 \\
\hline 20 & 182.1857 & 40 & 182.1857 & 69 & 0 \\
\hline
\end{tabular}

New energy curve design including wind power and photovoltaic power generation curve. Also adopt the method of summary on the related data for the reasonable design of curve, the difference is need combined with the actual situation to modify the related curve. Photovoltaic power generation of night, for example, should be revised to 0 , wind power output volatility and volatility of photovoltaic power output is not the same, and so on. This paper set up the initial volatility of photovoltaic power generation was $10 \%$, the average for the system as a whole load of 0.3 times; Wind power fluctuation was $20 \%$, the average for the whole load of 0.4 times. Need of special note is, there is only an initial curve, the design of the curve is not the end of the simulation curve, the related parameters can combines the actual conditions of the specific problems in the application or the emphasis of the research problem appropriately modified. New energy power generation of the initial curve output data as shown in table 3 and 4, the graph to Fig .3.
TABLE III. WIND POWER GENERATION INITIAL CURVE

\begin{tabular}{|c|c|c|c|c|c|}
\hline $\begin{array}{c}\text { Time } \\
\text { Point }\end{array}$ & $\begin{array}{c}\text { Maximum } \\
\text { capacity }\end{array}$ & $\begin{array}{c}\text { Time } \\
\text { Point }\end{array}$ & $\begin{array}{c}\text { Maximum } \\
\text { capacity }\end{array}$ & $\begin{array}{c}\text { Time } \\
\text { Point }\end{array}$ & $\begin{array}{c}\text { Maximum } \\
\text { capacity }\end{array}$ \\
\hline 1 & 322.998574 & 21 & 66.755234 & 41 & 96.0747631 \\
\hline 2 & 320.346874 & 22 & 53.5819349 & 42 & 111.899762 \\
\hline 3 & 315.959667 & 23 & 41.5958608 & 43 & 128.273044 \\
\hline 4 & 309.885019 & 24 & 30.9283336 & 44 & 145.015219 \\
\hline 5 & 302.189485 & 25 & 21.6962289 & 45 & 161.942857 \\
\hline 6 & 292.957381 & 26 & 14.0006956 & 46 & 178.870495 \\
\hline 7 & 282.289853 & 27 & 7.92604759 & 47 & 195.61267 \\
\hline 8 & 270.303779 & 28 & 3.53883997 & 48 & 211.985952 \\
\hline 9 & 257.13048 & 29 & 0.88713992 & 49 & 227.810951 \\
\hline 10 & 242.914286 & 30 & 0 & 50 & 242.914286 \\
\hline 11 & 227.810951 & 31 & 0.88713992 & 51 & 257.13048 \\
\hline 12 & 211.985952 & 32 & 3.53883997 & 52 & 270.303779 \\
\hline 13 & 195.61267 & 33 & 7.92604759 & 53 & 282.289853 \\
\hline 14 & 178.870495 & 34 & 14.0006956 & 54 & 292.957381 \\
\hline 15 & 161.942857 & 35 & 21.6962289 & 55 & 302.189485 \\
\hline 16 & 145.015219 & 36 & 30.9283336 & 56 & 309.885019 \\
\hline 17 & 128.273044 & 37 & 41.5958608 & 57 & 315.959667 \\
\hline 18 & 111.899762 & 38 & 53.5819349 & 58 & 320.346874 \\
\hline 19 & 96.0747631 & 39 & 66.755234 & 59 & 322.998574 \\
\hline 20 & 80.9714286 & 40 & 80.9714286 & 60 & 323.885714 \\
\hline & & & & & \\
\hline
\end{tabular}

TABLE IV. PV POWER GENERATION INITIAL CURVE

\begin{tabular}{|c|c|c|c|c|c|}
\hline $\begin{array}{c}\text { Time } \\
\text { Point }\end{array}$ & $\begin{array}{c}\text { Maximum } \\
\text { capacity }\end{array}$ & $\begin{array}{c}\text { Time } \\
\text { Point }\end{array}$ & $\begin{array}{c}\text { Maximum } \\
\text { capacity }\end{array}$ & $\begin{array}{c}\text { Time } \\
\text { Point }\end{array}$ & $\begin{array}{c}\text { Maximum } \\
\text { capacity }\end{array}$ \\
\hline 1 & 0 & 21 & 192.8479 & 41 & 170.85821 \\
\hline 2 & 0 & 22 & 202.7278 & 42 & 158.98946 \\
\hline 3 & 0 & 23 & 211.7174 & 43 & 146.7095 \\
\hline 4 & 0 & 24 & 219.718 & 44 & 134.15287 \\
\hline 5 & 0 & 25 & 226.6421 & 45 & 121.45714 \\
\hline 6 & 0 & 26 & 232.4138 & 46 & 0 \\
\hline 7 & 0 & 27 & 236.9698 & 47 & 0 \\
\hline 8 & 0 & 28 & 240.2602 & 48 & 0 \\
\hline 9 & 0 & 29 & 242.2489 & 49 & 0 \\
\hline 10 & 0 & 30 & 242.9143 & 50 & 0 \\
\hline 11 & 0 & 31 & 242.2489 & 51 & 0 \\
\hline 12 & 0 & 32 & 240.2602 & 52 & 0 \\
\hline 13 & 0 & 33 & 236.9698 & 53 & 0 \\
\hline 14 & 0 & 34 & 232.4138 & 54 & 0 \\
\hline 15 & 0 & 35 & 226.6421 & 55 & 0 \\
\hline 16 & 134.152871 & 36 & 219.718 & 56 & 0 \\
\hline 17 & 146.709503 & 37 & 211.7174 & 57 & 0 \\
\hline 18 & 158.989464 & 38 & 202.7278 & 58 & 0 \\
\hline 19 & 170.858213 & 39 & 192.8479 & 59 & 0 \\
\hline 20 & 182.185714 & 40 & 182.1857 & 60 & 0 \\
\hline
\end{tabular}




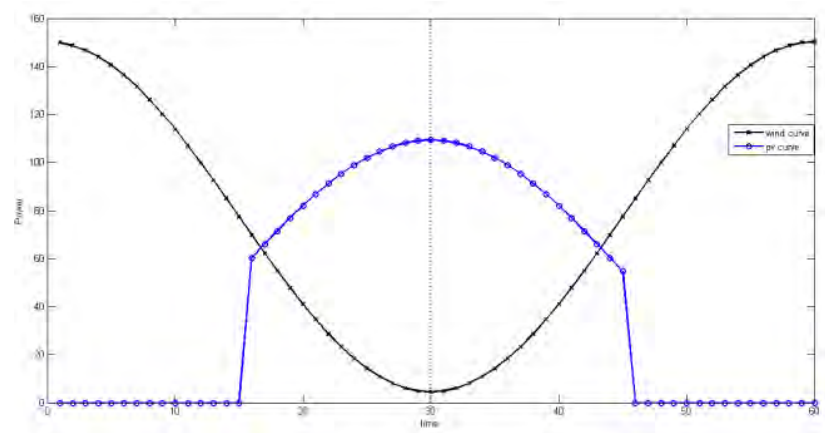

Figure 3. The initial generation power curve of new energy power

\section{THE SELECTION OF OPTIMIZATION ALGORITHM}

New energy grid runtime through some optimization algorithm controls the size of the capacity of the new energy power generation access networks, so as to make the new energy power generation in power supply system to achieve a best balance between the stability of the economy and safety. Looking for system optimal equilibrium is the essential connotation of the system of optimal power flow. The concept of optimal power flow first put forward by John casteen pentier French engineer in the early 1960 s, its core content is in the guarantee system of various constraint conditions under the condition of established, many of the variables in the control system by some means value target of the system to achieve the desired minimum or maximum. As a result of the optimal power flow including content is numerous, widely involved economic optimal control and scheduling of the system operation safety, power grid planning, etc; Optimal power flow, therefore, have been proposed since got rapid development, many excellent algorithms have been proposed.

The original dual method belongs to an important branch of interior-point method, it has strong practicability and appealing. The basis of the algorithm framework is established by a Meiddo, Monterior and others, then promotion by Kojima, etc to the complementary problem. The original-dual algorithm can easily be applied to nonlinear convex programming, nonlinear complementarity, variational inequality, semidefinite optimization and secondorder cone optimization problems such as field, has a similar approach in the best polynomial complex boundaries. This article will adopt this kind of method, which is the core of the system optimization research method, algorithm detailed steps as follows:

extreme-value proposition of the objective function, set up theconstraints in the problem domain;

$$
\begin{array}{ll} 
& \min f(X) \\
\text { s.t. } & G(X=0) \\
& H(X) \leq 0
\end{array}
$$

The inequality constraints of constraints into equality constraints, and modify the objective function. The core idea of this step is to put into Lagrange extremum problem with constraint condition equation form optimization inequality forms of extreme value problem.

$$
\begin{aligned}
& \min \left[f(X)-\gamma \sum_{m=1}^{n} \ln \left(Z_{m}\right)\right] \\
& G(X)=0 \\
& H(X)+Z=0 \\
& Z>0
\end{aligned}
$$

First optimality conditions. Appropriate transformation of the partial differential equations in (9), and obtain the equations of first-order optimality conditions for 0 .

$$
\mathrm{F}(X, Z, \lambda, \mu)=\left[\begin{array}{c}
f_{X}{ }^{T}+G_{X}{ }^{T} \lambda+H_{X}{ }^{T} \mu \\
{[\mu] Z-\gamma e} \\
G(\mathrm{X}) \\
H(\mathrm{X})+\mathrm{Z}
\end{array}\right]=0
$$

\section{CONCLUSION}

This paper introduces the design of new energy power supply structure based onstructure of IEEE30 power supply network, according to the inherent characteristics of PV and wind power generation simulation curve design of photovoltaic power generation, wind power generation simulation curve andsimulated load curve; using universal transmission line structure simplifies the structure of the power supply system; comparative analysis of advantages and disadvantages of various optimization algorithms. The final choice of primal dualoptimization algorithm as optimizing kernel algorithm.

\section{REFERENCES}

[1] J. Liang, O. G. Bellmunt and J. Ekanayake, "Control of multiterminal VSC-HVDC transmission for offshore wind power," Power Electronics and Applications, EPE '09, 13th ed, pp. 1-10, 2009.

[2] W. Y. Zhang, S. Z. Zhu and J. H. Zhengl, “ Impacts of Distributed Generation on Electric Grid and Selecting of Isolation Transformer," Transmission and Distribution Conference and Exhibition: Asia and Pacific, IEEE/PES. pp. 1-7, 2005.

[3] L. Wei, G. Joos and C. Abbey, “Wind Power Impact on System Frequency Deviation and an ESS based Power Filtering Algorithm Solution," Power Systems Conference and Exposition. PSCE' 06. IEEE PES. pp. 2077-2084. 2006.

[4] C. Chompoo, W. Lee and P. Fuangfoo, “ System impact study for the interconnection of wind generation and utility system," Industry Applications, IEEE Transactions on, vol. 41, pp. 163-168, April 2005.

[5] J. Wiik, J.O. Gjerde and T. Gjengedal, “ Steady state power system issues when planning large wind farms," IEEE Power Engineering Society Winter Meeting, vol. 233, pp. 366-371, 2002.

[6] J. V. Paatero and P. D. Lund, " Effect of energy storage on variations in wind power," Wind Energy, vol. 8, pp.421-441, Dec 2005.

[7] C. Wang and M. H. Nehrir, “ Analytical approaches for optimal placement of distributed generation sources in power systems," Power Systems, IEEE Transactions on, vol. 19, pp. 2068-2076, 2004.

[8] T. Hal and T. K. Saha, “ Investigation of power loss and voltage stability limits for large wind farm connections to a sub-transmission network," Power Engineering Society General Meeting, IEEE, vol. 12, pp. 2251-2256, Jun 20045. 
[9] N. T. Linh, " Voltage stability analysis of grids connected wind generators," //Industrial Electronics and Applications, 2009. ICIEA 2009. 4th IEEE Conference on. IEEE, pp. 2657-2660, 2009.
[10] I. Dobson, “ Observations on the geometry of saddle node bifurcation and voltage collapse in electrical power systems," Circuits and Systems I: Fundamental Theory and Applications, IEEE Transactions on,vol. 39, pp. 240-243, 1992. 